\title{
Sustained haemodynamic action of nitroglycerin ointment ${ }^{1}$
}

\author{
Steven G. Meister, Toby R. Engel, Nabil Guiha, Charles M. Furr, Gilson S. Feitosa, \\ Katherine Hart, and William S. Frankl \\ From the Medical College of Pennsylvania and Hospital, Philadelphia, Pennsylvania, U.S.A.
}

Intravenous vasodilators have been shown to improve the haemodynamic status of patients in congestive heart failure. However, neither intravenous nor sublingual preparations are suitable for chronic administration or use in ambulatory patients In this study, nitroglycerin ointment was administered to 11 patients in congestive heart failure. Mean pulmonary wedge and arterial pressures, as well as systemic blood pressures and heart rate were then monitored for 2 to 5 hours and compared with baseline values. Pulmonary wedge and arterial pressures, as well as systemic systolic arterial pressure, decreased significantly at 15 minutes after application and remained depressed for up to 5 hours. Systemic diastolic pressures fell significantly at 30 minutes and also remained significantly reduced for up to 5 hours. Thus, nitroglycerin ointment may be suitable for chronic vasodilator therapy of congestive heart failure.

Acute administration of systemic vasodilating drugs has been shown to improve the haemodynamic status of patients in congestive heart failure, with and without acute myocardial infarction (Miller et al., 1975; Flaherty et al., 1975; Shell and Sobel, 1974; Walinsky et al., 1974). The nitrates and phentolamine have in fact been effective in some patients refractory to conventional therapy (Guiha et al., 1974; Gold, Leinbach, and Sanders, 1972; Majid, Sharma, and Taylor, 1971).

Most studies to date have used potent, rapid acting intravenous preparations of sodium nitroprusside, nitroglycerin, phentolamine, or trimethaphan. These require intensive haemodynamic monitoring and precise control of infusion rates to avoid induction of dangerous systemic hypotension (Guiha et al., 1974; Walinsky et al., 1974). This manner of administration is necessarily restricted to the intensive care setting. More general clinical applicability would require a long-acting vasodilator preparation suitable for administration without intravenous infusion or frequent haemodynamic monitoring. Oral nitrate preparations have been proposed for this purpose (Franciosa et al., 1974;

Received 24 February 1976.

'Supported in part by grants from the Southeastern Pennsylvania Heart Association. Presented in part at the 25th annual Scientific Session of the American College of Cardiology, 26 February 1976.
Kasparian et al., 1975), but controversy persists regarding their efficacy and resistance to rapid hepatic transformation (Goldstein et al., 1971; Needleman, Lang, and Johnson, 1972).

Cutaneously administered nitroglycerin has the theoretical advantage of enhanced bioavailability because of direct absorption into the systemic circulation. It is similar in this regard to sublingual and intravenous preparations whose activity is readily seen but of brief duration (Goldstein $e t$ al., 1971; Goldstein and Epstein, 1973; Klaus et al., 1973). The cutaneous route might provide sustained activity on the basis of continuous absorption from a sizeable depot on the skin. In this connexion, nitroglycerin ointment has recently been shown to improve exercise tolerance in angina pectoris patients for at least 3 hours (Reichek et al., 1974).

The present study was undertaken to determine whether nitroglycerin ointment causes nitrate-like haemodynamic effects of sufficient magnitude and duration to be of potential value in therapy of congestive heart failure.

\section{Methods}

Eleven consecutive patients clinically suspected of having significant left ventricular dysfunction, and found to have pulmonary wedge pressures greater 
TABLE 1 Biographical data and baseline haemodynamic values

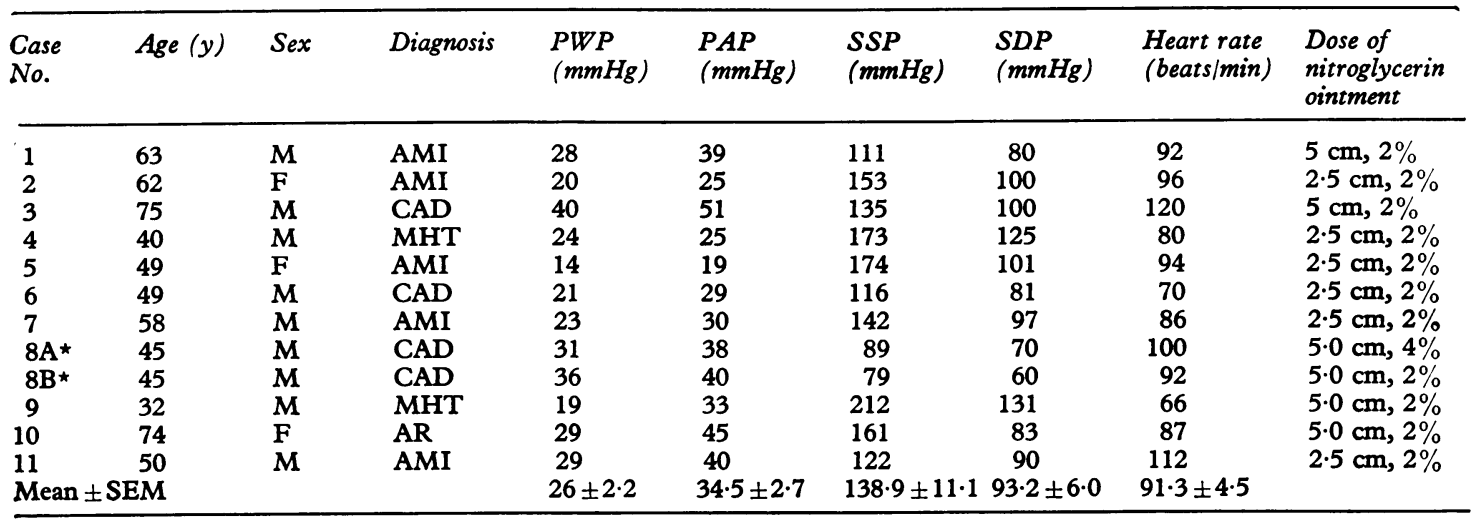

Abbreviations: AMI, acute myocardial infarction; CAD, chronic coronary arterial disease; MHT, malignant hypertension; $A R$, aortic valvular regurgitation; $P W P$, pulmonary wedge mean pressure; $P A P$, pulmonary arterial mean pressure; SSP, systemic arterial systolic pressure; SDP, systemic arterial diastolic pressure.

$\star$ Same patient studied on two separate occasions.

than $14 \mathrm{mmHg}$ were included in the study. Patients' age, sex, cardiac diagnosis, and control haemodynamic values are listed in Table 1 . One patient was studied on two separate occasions at an interval of 10 days before and after ventricular aneurysmectomy. No patient was given digitalis for the first time on the day of study. No patient previously on digitalis received greater than a maintenance dose of a digitalis preparation on the day of study. Only intravenous frusemide was used for diuresis and this was not administered within 4 hours before entry into the study. Informed written consent was obtained from all patients before study. Right heart catheterization was performed at the bedside, using No. 7 French Swan-Ganz catheters (Swan et al., 1970). Right heart pressures were measured, using an Ailtech Model M510 transducer and a Tektronix Model 412 pressure amplifier. Zero reference point was taken at the mid chest. Systemic systolic and diastolic pressures were measured by sphygmomanometry. Control values for pulmonary wedge pressure, pulmonary arterial pressure, systemic systolic and diastolic pressure, and heart rate were obtained twice at an interval of 30 minutes. No patient whose second control value for pulmonary wedge pressure was more than $5 \mathrm{mmHg}$ below the first value or less than $14 \mathrm{mmHg}$ was included in the study. Control values were taken as the average of both readings. Immediately after the second control reading, $2.5 \mathrm{~cm} 2$ per cent nitroglycerin ointment was applied to a $232 \mathrm{~cm}^{2}$ area of skin on the back or thighs and covered with an oc- clusive plastic dressing. Haemodynamic measurements were then made at 15 -minute intervals. If no appreciable fall in pulmonary wedge pressure was seen within 30 minutes, a second $2.5 \mathrm{~cm}$ nitroglycerin ointment was applied to another $232 \mathrm{~cm}^{2}$ area and measurements were repeated. If there was still no fall in pulmonary wedge pressure (Case 8A) the 2 per cent nitroglycerin ointment was removed and replaced by $5 \mathrm{~cm} 4$ per cent nitroglycerin ointment applied to two separate $232 \mathrm{~cm}^{2}$ areas. Once a fall of pulmonary wedge pressure $>5 \mathrm{mmHg}$ was observed, subsequent measurements were made at 30 to 60 minute intervals for 2 to 5 hours.

Control pressures and heart rates were expressed as mean \pm standard error of the mean (SEM). The haemodynamic changes attributed to nitroglycerin ointment were expressed as mean differences from control values \pm standard error of the difference (SED). Statistical evaluation was performed using Student's t test for paired data.

In view of the necessity to withhold inotropic or diuretic agents during the study period, use of a placebo ointment was considered unjustified.

\section{Results}

Nitroglycerin ointment caused significant reductions in pulmonary wedge pressure, pulmonary arterial pressure, and systemic blood pressures that were maintained for up to 5 hours. Mean differences 

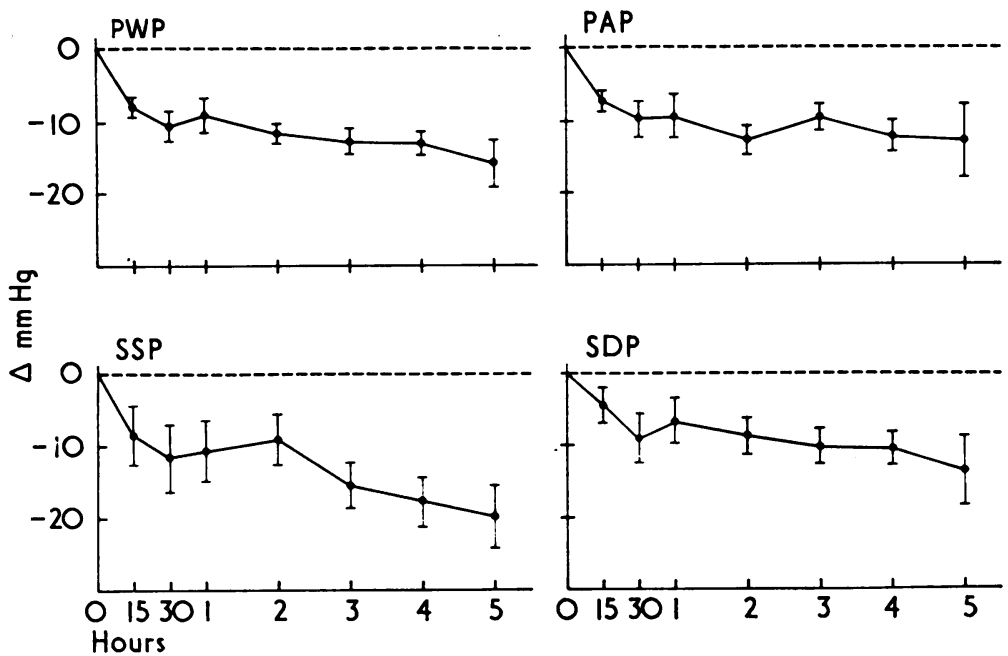

FIG. 1 Haemodynamic changes after application of nitroglycerin ointment. Results as mean differences from baseline $\pm S E D$. PWP, pulmonary wedge mean pressure; $P A P$, pulmonary arterial mean pressure; SSP, systemic arterial systolic pressure; SDP, systemic arterial diastolic pressure.

from control for all values are listed in Table 2 and illustrated in Fig. 1.

Pulmonary wedge pressure was significantly reduced by $7.9 \mathrm{mmHg}$ at 15 minutes $(\mathrm{P}<0.005)$. Maximum reductions of $12.9 \mathrm{mmHg}$ and 15.8 $\mathrm{mmHg}$ occurred at 4 and 5 hours, respectively ( $P<0.005$ for both).

Similary, pulmonary artery pressure was significantly reduced by $7.3 \mathrm{mmHg}(P<0.005)$ at 15 minutes. Peak reductions were $12 \cdot 1 \mathrm{mmHg}$ and $12.9 \mathrm{mmHg}$ at 4 and 5 hours $(P<0.005$ and $<0.05$ ).

Systemic systolic pressure was also significantly reduced at 15 minutes by $8.5 \mathrm{mmHg}(\mathrm{P}<0.05)$.
Again, peak effect was observed at 4 and 5 hours when reductions were $17.7 \mathrm{mmHg}$ and $19.8 \mathrm{mmHg}$, respectively $(\mathrm{P}<0.005$ and $<0.025)$.

The reduction in systemic diastolic pressure was not significant until 30 minutes and was $9.0 \mathrm{mmHg}$ $(P<0.025)$ at that time. Again, peak reductions of $10.5 \mathrm{mmHg}$ and $13.5 \mathrm{mmHg}$ were noted at 4 and 5 hours $(P<0.005$ and $<0.05$, respectively).

Five of six patients showed return of haemodynamic levels toward normal within one hour of removal of nitroglycerin ointment.

Although no attempt was made to quantify symptoms or physical signs, 4 patients who were dyspnoeic during the control period had relief of

TABLE 2 Changes in haemodynamic parameters after administration of nitroglycerin ointment

\begin{tabular}{|c|c|c|c|c|c|c|c|}
\hline & $15 \min$ & $30 \mathrm{~min}$ & $1 \mathrm{hr}$ & $2 h r$ & $3 h r$ & $4 h r$ & $5 h r$ \\
\hline & $\star \star \star$ & $\star \star \star \star$ & $\star \star \star \star$ & $\star \star \star$ & $\star \star \star$ & $\star \star \star \star$ & $\star \star$ \\
\hline PWP (mmHg) & $\begin{array}{r}-7 \cdot 9 \pm 1 \cdot 5 \\
\star \star \star\end{array}$ & $\begin{array}{r}-10 \cdot 6 \pm 2 \cdot 3 \\
\star \star \star\end{array}$ & $\begin{array}{r}-9 \cdot 0 \pm 2 \cdot 4 \\
\star \star \star\end{array}$ & $\begin{array}{r}-12 \cdot 5 \pm 2 \cdot 4 \\
\star \star \star\end{array}$ & $-12 \cdot 7 \pm 1 \cdot 8$ & $-12 \cdot 9 \pm \underset{\star \star \star}{1 \cdot 7}$ & $-15 \cdot 8 \pm 3 \cdot 3$ \\
\hline PAP (mmHg) & $\begin{array}{r}-7 \cdot 3 \pm 1 \cdot 5 \\
\star\end{array}$ & $\begin{array}{r}-9 \cdot 6 \pm 2 \cdot 5 \\
\star \star\end{array}$ & $\begin{array}{r}-9.4 \pm 2.9 \\
\star \star\end{array}$ & $-12 \cdot 8 \pm 2 \cdot 1$ & $-9 \cdot 5 \pm 1 \cdot 7$ & $-12 \cdot 1 \pm \underset{\star \star \star}{2 \cdot 1}$ & $-12 \cdot 9 \pm 5 \cdot 1$ \\
\hline SSP (mmHg) & $-8 \cdot 5 \pm 4 \cdot 2$ & $-11 \cdot 6 \pm \underset{\star \star}{4 \cdot 6}$ & $-10 \cdot 8 \pm 4 \cdot 2$ & $\begin{array}{r}-9 \cdot 0 \pm 3 \cdot 6 \\
\star \star \star\end{array}$ & $-15 \cdot 3 \pm \underset{\star \star \star}{3 \cdot 2}$ & $-17 \cdot 7 \pm 3 \cdot 4$ & $-19 \cdot 8 \pm 4 \cdot 3$ \\
\hline $\begin{array}{l}\text { SDP }(\mathrm{mmHg}) \\
\text { HR (beats/min) } \\
\text { No. of patients }\end{array}$ & $\begin{array}{l}-4 \cdot 4 \pm 2.4 \\
-0.8 \pm 1.9 \\
10\end{array}$ & $\begin{array}{l}-9 \cdot 0 \pm 3 \cdot 4 \\
-1 \cdot 1 \pm 3 \cdot 5 \\
10\end{array}$ & $\begin{aligned} &-6 \cdot 6 \pm 3 \cdot 2 \\
&-2 \cdot 9 \pm 3 \cdot 0 \\
& 12\end{aligned}$ & $\begin{aligned}-8 \cdot 7 & \pm 2 \cdot 5 \\
-1 \cdot 2 & \pm 3 \cdot 8 \\
12 & \end{aligned}$ & $\begin{array}{r}-10 \cdot 3 \pm 2 \cdot 4 \\
-0 \cdot 3 \pm 4 \cdot 5 \\
11\end{array}$ & $\begin{aligned}-10 \cdot 5 & \pm 2 \cdot 4 \\
-3 \cdot 9 & \pm 3 \cdot 6 \\
11 & \end{aligned}$ & $\begin{array}{r}-13 \cdot 5 \pm 4 \cdot 7 \\
4^{-8 \cdot 5 \pm 5 \cdot 3}\end{array}$ \\
\hline
\end{tabular}

Abbreviations : PWP, pulmonary wedge pressure; PAP, pulmonary arterial mean pressure; SSP, systemic arterial systolic pressure; SDP, systemic arterial diastolic pressure; HR, heart rate; ${ }^{\star}=\mathbf{P}<0.05 ; \star \star=P<0.025 ; \star \star \star=P<0.005$. 


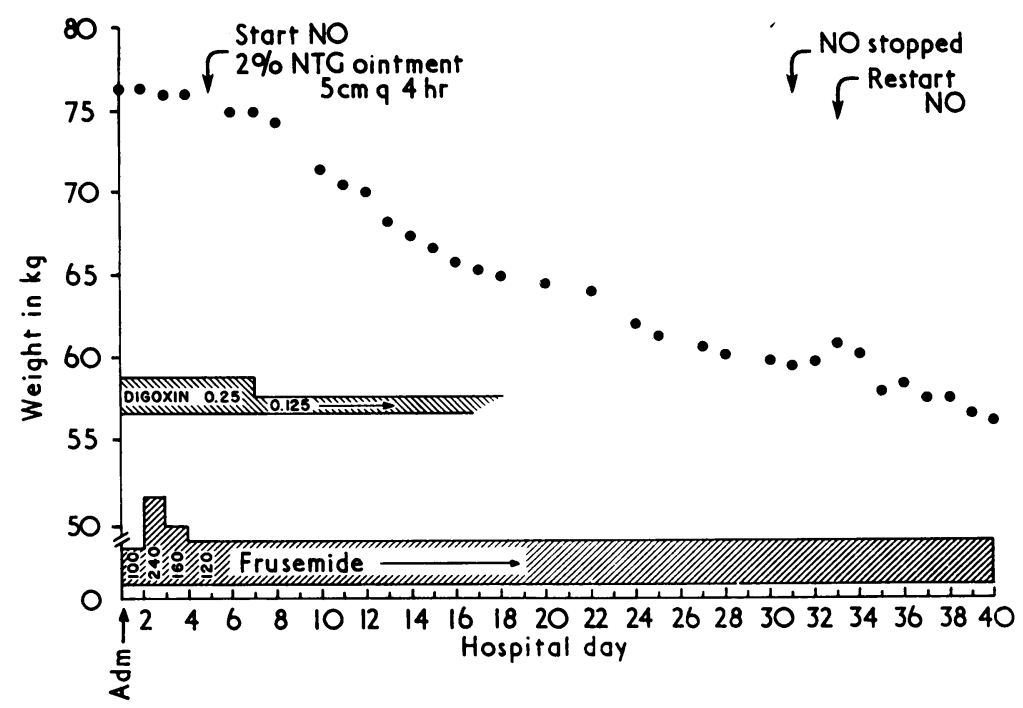

FIG. 2 Daily weights in Case 10 with severe biventricular failure who was treated with maintenance nitroglycerin ointment (NO) in addition to digoxin and frusemide (see text).

this symptom after nitroglycerin ointment was applied. A 74-year-old woman (Case 10) had severe biventricular failure and anasarca on the basis of aortic regurgitation. After 4 days of treatment with bed rest, sodium restriction, digoxin, and high doses of frusemide, she had lost only $0.45 \mathrm{~kg}$. She was then admitted to this study and given $5 \mathrm{~cm} 2$ per cent nitroglycerin ointment which reduced her pulmonary wedge pressure from 29 to $12 \mathrm{mmHg}$, and her dyspnoea improved. Subsequently, she was maintained on this dose of nitroglycerin ointment every 4 hours, as well as maintenance digoxin and frusemide, and had prompt onset of a sustained diuresis. Her daily weights and medicines given are plotted in Fig. 2. When nitroglycerin ointment was discontinued for 3 days she regained $1.8 \mathrm{~kg}$. Weight loss then resumed when nitroglycerin ointment was reinstituted.

No patient developed symptoms or physical signs of systemic arterial hypotension during the study. Several patients complained of headache. One patient noted mild burning at the site of 4 per cent nitroglycerin ointment application.

\section{Discussion}

The beneficial effects of sublingual or intravenous vasodilating drugs in congestive heart failure have been attributed to simultaneous reduction of left ventricular outflow impedance and filling pressure caused, respectively, by arteriolar and venous vaso- dilatation. These changes permit the left ventricle to operate at a smaller cavity size with consequently improved mechanical efficiency and reduced myocardial oxygen demand. The observed haemodynamic effects include distinct reduction in pulmonary wedge pressures and modest reduction in systemic arterial pressures without change in heart rate (Miller et al., 1975; Gold et al., 1972; Flaherty et al., 1975; Franciosa et al., 1972). Cardiac output response is variable and appears to be a function of left ventricular filling pressure (Miller et al., 1975; Gold et al., 1972; Johnson, Fairley, and Carter, 1959; Walinsky et al., 1974; Williams, Amsterdam, and Mason, 1975). Since our intention was to examine the duration of action of nitroglycerin ointment, only those variables known to change unidirectionally in response to vasodilators were monitored, and cardiac output was not included.

In this study, administration of nitroglycerin ointment to patients with left ventricular dysfunction resulted in significant lowering of pulmonary wedge pressure, pulmonary arterial pressure, and systemic arterial pressures, characteristic of that seen with intravenous or sublingual vasodilators. Significant reductions were usually noted at 15 to 30 minutes after application and a significant effect persisted for up to 5 hours. Clinically important hypotension was not encountered. Though considerable individual variation was noted, average coronary perfusion pressure (estimated by subtraction of wedge pressure from systemic diastolic 
pressure) was not significantly decreased at any measured interval.

Not surprisingly, the size of the application area played a critical role in producing these haemodynamic effects. No appreciable haemodynamic changes were observed when smaller, $103 \mathrm{~cm}^{2}$, application areas were used. Furthermore, about half of our subjects required a doubling of the initial dose and application area for achievement of an adequate response.

For the purpose of this study, reduction of pulmonary wedge pressure was used as an objective indicator of drug effectiveness. Our experience suggests that for routine use it would be sufficient to monitor systemic blood pressure while increasing the dose and application area until a satisfactory clinical response is observed. In this connexion, 3 of our study patients who were symptomatic and poorly responsive to conventional therapy for congestive heart failure were maintained on nitroglycerin ointment after the study. All reported improvement in their congestive symptoms, and untoward effects other than headaches were not observed. The clinical course in one patient with biventricular failure and anasarca has been described above and in Fig. 2.

The sustained haemodynamic activity observed in our study suggests that nitroglycerin ointment may prove applicable to other disease states for which vasodilator therapy is appropriate, such as in prophylaxis of angina pectoris. Though this study did not deal specifically with angina, our demonstration of sustained pharmacological activity is consistent with the exercise studies of Reichek et al. (1974).

Recent studies in both experimental animals and man suggest that vasodilator therapy during acute myocardial infarction may limit the extent and sequelae of myocardial necrosis (Flaherty et al., 1975; Shell and Sobel, 1974; Smith et al., 1973; Borer et al., 1974). If future investigations confirm these findings, nitroglycerin ointment may provide a convenient means of reducing myocardial oxygen demand in routine management of acute myocardial infarction.

In summary, our data indicate that nitroglycerin ointment causes a sustained haemodynamic response similar to that seen with acutely administered vasodilators. With careful adjustment of dosage and application area it can be used in ambulatory patients without induction of dangerous hypotension. Accordingly, it has potential value in chronic vasodilator therapy of congestive heart failure and merits consideration for use in other clinical situations for which sustained vasodilatation is appropriate.

\section{References}

Borer, J. S., Kent, K. M., Goldstein, R. E., and Epstein, S. E. (1974). Nitroglycerin-induced reduction in the incidence of spontaneous ventricular fibrillation during coronary occlusion in dogs. American fournal of Cardiology, 33, 517.

Flaherty, J. T., Reid, P. R., Kelly, D. T., Taylor, D. R., Weisfeldt, M. L., and Pitt, B. (1975). Intravenous nitroglycerin in acute myocardial infarction. Circulation, 51, 132.

Franciosa, J. A., Guiha, N. H., Limas, C. J., Rodriguera, E., and Cohn, J. N. (1972). Improved left ventricular function during nitroprosside infusion in acute myocardial infarction. Lancet, 1, 650.

Franciosa, J. A., Mikulic, E., Cohn, J. N., Jose, E., and Fabie, A. (1974). Hemodynamic effects of orally administered isosorbide dinitrate in patients with congestive heart failure. Circulation, 50, 1020.

Gold, H. K., Leinbach, R. C., and Sanders, C. A. (1972). Use of sublingual nitroglycerin in congestive failure following acute myocardial infarction. Circulation, 46, 839.

Goldstein, R. E., and Epstein, S. E. (1973). Nitrates in the prophylactic treatment of angina pectoris. Circulation, 48, 917.

Goldstein, R. E., Rosing, D. R., Redwood, D. R., Beiser, G. D., and Epstein, S. E. (1971). Clinical and circulatory effects of isosorbide dinitrate. Comparison with nitroglycerin. Circulation, 43, 629.

Guiha, N. J., Cohn, J. N., Mikulic, E., Franciosa, J. A., and Limas, C. J. (1974). Treatment of refractory heart failure with infusion of nitroprusside. New England fournal of Medicine, 291, 587.

Johnson, J. B., Fairley, A., and Carter, C. (1959). Effects of sublingual nitroglycerin on pulmonary arterial pressure in patients with left ventricular failure. Annals of Internal Medicine, 50, 34.

Kasparian, H., Wiener, L., Duca, P. R., Gottlieb, R. S., and Brest, A. N. (1975). Comparative hemodynamic effects of placebo and oral isosorbide dinitrate in patients with significant coronary artery disease. American Heart fournal, 90, 68.

Klaus, A., Zaret, B., Pitt, B., and Ross, R. S. (1973). Comparative evaluation of sublingual long acting nitrates in angina pectoris. American fournal of Cardiology, 31, 142.

Majid, P. A., Sharma, B., and Taylor, S. H. (1971). Phentolamine for vasodilator treatment of severe heart-failure. Lancet, 2, 719.

Miller, R. R., Vismara, L. A., Zelis, R., Amsterdam, E. A., and Mason, D. T. (1975). Clinical use of sodium nitroprusside in chronic ischemic heart disease. Effects on peripheral vascular resistance venous tone and on ventricular volume, pump and mechanical performance. Circulation, 51, 328.

Needleman, P., Lang, S., and Johnson, E. M. (1972). Organic nitrates: relationship between biotransformation and rational angina pectoris therapy. Fournal of Pharmacology and Experimental Therapeutics, 181, 489.

Reichek, N., Goldstein, R. E., Redwood, D. R., and Epstein, S. E. (1974). Sustained effects of nitroglycerin ointment in patients with angina pectoris. Circulation, 50, 348.

Shell, W. E., and Sobel, B. E. (1974). Protection of jeopardized ischemic myocardium by reduction of ventricular afterload. New England fournal of Medicine, 291, 481.

Smith, E. R., Redwood, D. R., McCarron, W. E., and Epstein, S. E. (1973). Coronary artery occlusion in the conscious dog. Effects of alterations in arterial pressure produced by nitroglycerin, hemorrhage, and alpha-adrenergic agonists on the degree of myocardial ischemia. Circulation, 47, 51 . 
Swan, H. J. C., Ganz, W., Forrester, J., Marcus, H., Diamond, G., and Chonette, D. (1970). Catheterization of the heart in man with use of a flow-directed balloon-tipped catheter. New England fournal of Medicine, 283, 447.

Walinsky, P., Chatterjee, K., Forrester, J., Parmley, W. W., and Swan, H. J. C. (1974). Enhanced left ventricular performance with phentolamine in acute myocardial infarction. American fournal of Cardiology, 33, 37.
Williams, D. O., Amsterdam, E. A., and Mason, D. T. (1975). Hemodynamic effects of nitroglycerin in acute myocardial infarction. Decrease in ventricular preload at the expense of cardiac output. Circulation, 51, 421.

Requests for reprints to Dr. Steven G. Meister, The Medical College of Pennsylvania, 3300 Henry Avenue, Philadelphia, Pennsylvania 19129, U.S.A. 